\title{
Gender Differentials and the Mathematics Performance of Grade 10 to 12 Learners at the Dilanedi Schools
}

\author{
Moeketsi Simon Mosia \\ School of Mathematics Natural Sciences and Technology Education, University of the Free State, South Africa \\ Email: MosiaMS@ufs.ac.za
}

\section{Doi:10.5901/mjss.2014.v5n23p1426}

\begin{abstract}
The aim of the study is to analyse how gender as a variable continues to have an impact on the performance of learners in Grade 10 to 12 mathematics, even at the Dinaledi Schools. The sample has the following characteristics: 592 Grade 10 learners, comprising 254 boys and 338 girls; 2415 Grade 11 learners, comprising 1018 girls and 1397 boys; and 1636 boys and 611 girls in Grade 12. The study uses secondary data collected by means of a mathematics questionnaire on different cognitive levels to diagnose learners' difficulties in mathematics. The items of questionnaire were clustered into five constructs, Manipulative Procedural Knowledge, Logical Reasoning, Problem Solving, Number Concept and Function concept. The study employed the one-way analyses of variance and t-test, testing the hypothesis that there is no difference in the mean scores of boys and girls in the given construct. The results showed that there is no significant difference in boys' and girls' mean scores for all the constructs in both Grade 10 and 11. However, in the Grade 12 class there was a signification difference in the mean scores of boys and girls in manipulative procedural knowledge and function concept in favour of boys.
\end{abstract}

Keywords: Manipulative Procedural Knowledge, Logical Reasoning, Problem Solving, Number Concept and Function concept

\section{Introduction}

The aim of the study is to analyse how gender as a variable continues to have an impact on the performance of learners of mathematics in Grade 10 to 12, even at the Dinaledi Schools. As early as the 1980s, studies reported the disparities between in boys' and girls' mathematics performance (Benbow \& Stanley, 1983; Klein \& Starkey, 1988). Mullis et al.'s (2000) results show that there is a small difference between the average performance of boys and girls in Grade 4 to Grade 8 mathematics classes, but the gap increases in senior classes. Matteucci \& Mignani (2011) have investigated the disparities in junior classes of high school and their results showed a significant difference between boys' and girls' average performance in favour of boys. Furthermore, it is reported that the gaps increase even more amongst the boys and girls who achieves best (Benbow \& Stanley, 1983; Benbow, 1988, PISA, 2012).

In contrast, other studies reported that, over the years, the gap between boys' and girls' performance in mathematics has narrowed and even closed. For example, Robinson and Lubienski's (2013) study has investigated males' and females' performance in mathematics and reading, including when the first gender gap appears, using K-8 national longitudinal data. Their results have shown that there is no gap between boys' and girls' mathematics performance. Fryer and Levitt's (2009) findings, in agreement with Robinsons et al.'s (2013) results, state that there are no significant differences between boys' and girls' mathematics performance.

The purpose of the Dinaledi Schools initiative is to improve the learners' performance in mathematics and physical science, with special reference to girls. This study consequently evaluates the progress that this initiative has made, given that in the Grade 12 Nation Senior Certificate Examinations we have observed that girls' performance in mathematics has improved greatly (DoE, 2010-2013). In order to make the study manageable, the paper will investigate gender disparities in the following construct: manipulative procedural knowledge, logical reasoning, problem solving, number concept, and function concept.

\section{Literature Review}

Most of the studies pertaining to gender disparities in mathematics are based on the data observed from the test scores, for example, the study by Vesterlund and Niederle (2010), explaining the gender gap in Math Test Scores, with no special reference to any mathematics skill. Livneh and Ayalon (2013) have used the national examination as data collection method and their results support the claim that boys perform better than girls do in mathematics. The study by Chung and 
Kim (2012) has used non-test scores data collection and non-mathematical skills data, since the data collected were with regard to family orientation, personal achievement, goal orientation, students' perceptions of classroom goal orientations, students' perceptions of parent goal orientations, students' perceptions of parent's motivating styles, and students' selfregulated motivation.

Furthermore, Ghazvini and Khajehpour (2011) have investigated gender differences in factors affecting the academic performance of high school students by using a locus of control questionnaire self-concept and LASSI. However, the study by Agah, Lamido and Utibe (2013) has examined the senior secondary school of learners' logical reasoning and mathematics achievement. The findings of their study show that logical reasoning is not sensitive to gender (Agah et al. 2013). Vasilyeva and Ganley (2011) have investigated the difference between the sexes in the relation between maths performance, spatial skills and attitudes, and their results attest to the claim that boys are better than girls are at problem solving.

Carr, Steiner, Kyser and Biddlecomb (2008) have extensively explored the gender differences in mathematics competency. Carr et al. (2008) have explored boys' and girls' correct choice of a strategy to solve a problem, fluency, the accuracy, manipulative strategies and confidence in a Grade 2 mathematics class. This study reports that manipulative procedural knowledge is gender sensitive. Moreover, gender differences were most evident in fluency and the types of strategies used in favour of boys.

The literature review shows that most of the studies in gender differences in mathematics, according to the empirical data analysed are non-content based and if it is, it does not assess specific mathematics skills. However, Carr et al. (2008) seem to assess most mathematics skills, but in a Grade 2 mathematics class. In this study, we will investigate if gender differences exist in Grade 10,11 and 12 mathematics classes. In addition, this study assesses more specific mathematics skills, namely manipulative procedural knowledge, logical reasoning, problem solving, number concept, and function concept in order to measure mathematical competency.

\section{Methodology}

\subsection{Participants}

This section is concerned with the design of an instrument that was used to collect the data. This study uses secondary data that were collected through the administration of a questionnaire to Grade 10 to 12 mathematics learners at Dinaledi Schools in the North-West Province in 2013. The questionnaire consists of two sections, A and B. Section A comprises 45 mathematics questions, which were structured in such a way that different cognitive levels are assessed for the purpose of diagnosing learners' difficulties in understanding mathematics. Section B is constructed to gather the biographical information of the learners. There are 592 Grade 10 learners, comprising 254 boys and 338 girls; 2415 Grade 11 learners, comprising 1018 girls and 1397 boys; and a Grade 12 class with 1636 boys and 611 girls.

\subsection{Validity and reliability}

To ensure the validity and reliability of the instrument, the mathematics items included in the instrument were selected in order to assess different cognitive levels, as prescribed by the FET Mathematics curriculum. This instrument was designed and then moderated by the mathematics subject advisor in the North-West Province. Furthermore, to guarantee the validity of the instrument, the questionnaire was administered under the supervision of researchers and teachers.

\subsection{Data analysis}

The study employed a t-test and one-way analysis of variance to analyse the data, using the Matlab statistical software package. We tried to establish whether there was a significant difference between the mean scores of boys and girls.

\section{Findings and Discussions}

Figure 1, 2 and 3 show the average scores per construct for Grades 10, 11 and 12, respectively. In these figures, the broken bars denote the boys' responses, while the solid bars denote the girls' responses. 


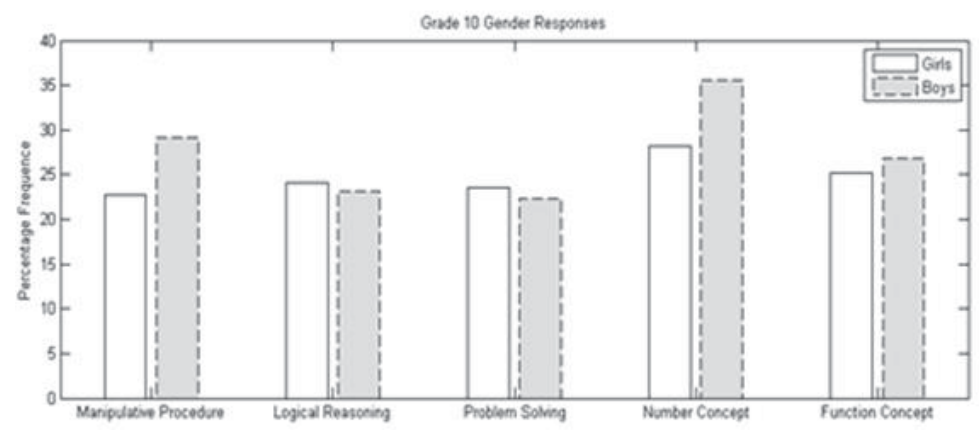

Figure 1: Grade 10 construct responses

When one looks at the Grade 10 chart with regard to manipulative procedural knowledge and number concept, the boys outperformed the girls with an average of $29,10 \%$ and $35,52 \%$, respectively. However, in other constructs there seems to be no significant difference.

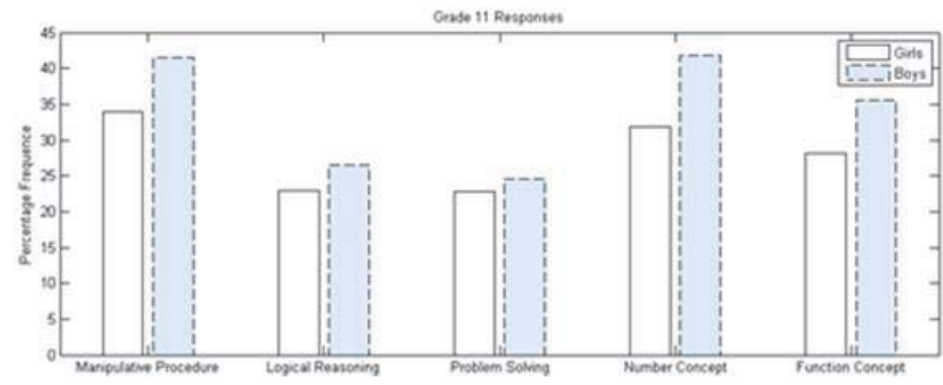

Figure 2: Grade 11 construct responses

Figure 2 above sketches the Grade 11 trend regarding boys' and girls' performance. The empirical evidence shows that the boys outperformed the girls in manipulative procedural knowledge, with an average of $41,49 \%$ for boys and $33,94 \%$ for girls; and in number concept with an average of $41,75 \%$ and $31,93 \%$, respectively. Moreover, boys attained an average of $35,52 \%$ average on function concept and girls $28,10 \%$. Furthermore, it should be noted that even in all other constructs, boys have performed slightly better than girls (see Figure 2). In general, the Grade 11 learners' performance seems to have increased slightly, compared to those of Grade 10.

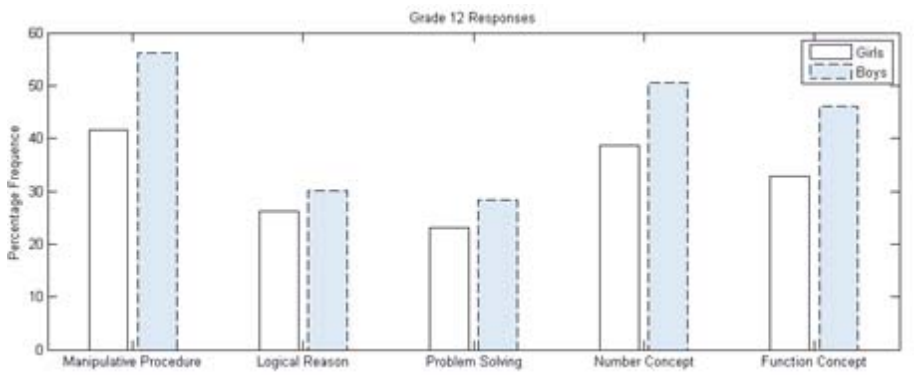

Figure 3: Grade 12 construct responses

Figure 3 sketches the trend of gender performance of Grade 12 learners in the five constructs as shown on the x-axis. From this chart, one can clearly see that the boys outperform girls in all the constructs. Moreover, we observed an increase in the performance of boys, compared to the preceding grades. 


\subsection{One-way analysis of variance and t-test}

\subsubsection{Grade 10 results and discussion}

Table 1: Grade 10 one-way analysis of variance

\begin{tabular}{|l|c|c|c|c|c|}
\hline Constructs & DF & SS & MS & F-Value & Significant level \\
\hline Manipulative Procedure & 1 & 243.16 & 243.16 & 2.96 & 0.0994 \\
\hline Logical Reasoning & 1 & 4.302 & 4.3018 & 0.11 & 0.7427 \\
\hline Problem Solving & 1 & 5.862 & 5.8619 & 0.12 & 0.7369 \\
\hline Number Concept & 1 & 107.956 & 107.956 & 1.86 & 0.2212 \\
\hline Function Concept & 1 & 16.9 & 16.9001 & 0.22 & 0.6425 \\
\hline
\end{tabular}

Table 2: Grade 10 t-test

\begin{tabular}{|l|c|c|c|c|}
\hline Constructs & DF & SD & t-value & Significant level \\
\hline Manipulative Procedure & 22 & 9.0637 & -1.7204 & 0.0994 \\
\hline Logical Reasoning & 16 & 6.2093 & 0.3340 & 0.7427 \\
\hline Problem Solving & 16 & 7.0830 & 0.3418 & 0.7369 \\
\hline Number Concept & 6 & 7.6109 & -1.3652 & 0.2212 \\
\hline Function Concept & 20 & 8.7227 & -0.4713 & 0.6425 \\
\hline
\end{tabular}

The results of manipulative procedural knowledge in Table 1 and 2 show that there is no significant difference in boys' and girls' performance in Grade 10 on items concerned with manipulative procedural knowledge, since we have a p-value of $0.0994>0.05$ significant level. Therefore, we fail to rejects the null hypothesis that there is no difference between the mean scores of boys and girls in the Grade 10 class. However, due to the magnitude of the p-value in a context of social science, perhaps one could say that in the Grade 10 class it seems to be worth commenting on manipulative procedural knowledge. Given that we are working in a social context, one could still argue that the gender difference in the boys' mean scores on manipulative procedural knowledge seems to be higher than that of the girls, as shown in Figure 1. The p-value of 0.7427 for logical reasoning is displayed in Table 1 and 2. This implies that we fail to reject the null hypothesis that the mean scores for boys are not different. This means that the logical reasoning is not gender sensitive. Moreover, a $\mathrm{p}$-value of 0.7369 was obtained from both the t-test and one-way analysis of variance. Based on these results, one can conclude that there is no significant difference between boys' and girls' performance in problem-solving items. This means that mathematical problem solving skills are not gender sensitive. This is in agreement with the findings by Randhawa (1987) that in the Grade 4 class there is no significant difference between boys' and girls' performance in mathematical problem solving skills, with special reference to analytical skills. In the last two, construct number and function concept, the p-values are 0.2212 and 0.6425 , respectively. These two constructs do not seem to be gender sensitive, since we fail to reject the null hypothesis that there is no difference between the mean scores of boys and girls at a significant level of 0.05 .

\subsubsection{Grade 11 results and discussion}

Table 3: Grade 11 one-way analysis of variance

\begin{tabular}{|l|c|c|c|c|c|}
\hline Constructs & DF & SS & MS & F-Value & Significant level \\
\hline Manipulative Procedure & 1 & 341.5 & 341.519 & 1.95 & 0.1763 \\
\hline Logical Reasoning & 1 & 57.09 & 57.086 & 0.33 & 0.5742 \\
\hline Problem Solving & 1 & 13.63 & 13.6328 & 0.21 & 0.6537 \\
\hline Number Concept & 1 & 192.859 & 192.859 & 3.46 & 0.1122 \\
\hline Function Concept & 1 & 303.04 & 303.047 & 3.57 & 0.0732 \\
\hline
\end{tabular}


Table 4: Grade 11 t-test

\begin{tabular}{|l|c|c|c|c|}
\hline Constructs & DF & SD & t-test & Significant level \\
\hline Manipulative Procedure & 22 & 13.2281 & -1.3970 & 0.1763 \\
\hline Logical Reasoning & 16 & 13.1706 & -0.5737 & 0.5742 \\
\hline Problem Solving & 16 & 8.0756 & -0.4572 & 0.6537 \\
\hline Number Concept & 6 & 7.4665 & -1.8600 & 0.1122 \\
\hline Function Concept & 20 & 9.2074 & -1.8906 & 0.0732 \\
\hline
\end{tabular}

The results exhibited in Table 3 and 4 report p-values that are greater than the significant 0.05 level for all five constructs. This means that we fail to reject the null hypothesis that there is no difference between mean scores of boys and girls for all the constructs. Therefore, based on these finding, one can conclude that in Grade 11 for all constructs the boys didn't perform significantly better than the girls do. The five mathematical skills do not seem to be gender sensitive. However, another observation worth commenting on is that the general results seem to be increasing as you move between the grade 10, 11 and 12 (see, Figure 1 and 2).

\subsubsection{Grade 12 results and discussion}

Table 5: Grade 12 one-way analysis of variance

\begin{tabular}{|l|c|c|c|c|c|}
\hline Constructs & DF & SS & MS & F-Value & Significant level \\
\hline Manipulative Procedure & 1 & 1289.21 & 1289.21 & 4.75 & 0.0403 \\
\hline Logical Reasoning & 1 & 67.17 & 67.174 & 0.24 & 0.6278 \\
\hline Problem Solving & 1 & 121.93 & 121.928 & 1.49 & 0.2396 \\
\hline Number Concept & 1 & 287.253 & 287.253 & 2.63 & 0.1561 \\
\hline Function Concept & 1 & 961.45 & 961.445 & 7.2 & 0.0143 \\
\hline
\end{tabular}

Table 6: Grade 12 t-test

\begin{tabular}{|l|c|c|c|c|}
\hline Constructs & DF & SD & t-value & Significant level \\
\hline Manipulative Procedure & 22 & 16.4803 & -2.1787 & $0.0403^{*}$ \\
\hline Logical Reasoning & 16 & 16.5828 & -0.4942 & 0.6278 \\
\hline Problem Solving & 16 & 9.0405 & -1.2214 & 0.2396 \\
\hline Number Concept & 6 & 10.4537 & -1.6213 & 0.1561 \\
\hline Function Concept & 20 & 11.5524 & -2.6841 & $0.0143^{\star}$ \\
\hline
\end{tabular}

*denotes significant

Figure 3 captures Grade 12 learners' performance, which shows an increase in the mean scores of both girls and boys relative to Grades 10 and 11 (see Figure 1 and 2). Logical reasoning, problem solving and number concept, with p-values $0.6278,0.2396$ and 0.1561 greater than the significant 0.05 level, respectively, are not sensitive to gender, since we fail to reject the null hypothesis that there is no difference between the mean scores of boys and girls. However, manipulative procedural knowledge has a p-value of 0.0403 , which is less than the significant 0.05 level. This implies that we reject the null hypothesis of no difference between the mean scores of boys and girls. The manipulative procedural knowledge in the Grade 12 class is gender sensitive. This means that the boys outperformed the girls in manipulative procedural knowledge, which attests to the findings of the study by ChanLin (2001) that boys perform better than girls do in procedural knowledge. Moreover, for function concept we have a p-value of 0.0143 , which indicates that, according to the difference observed in function concept in Figure 3 , the boys outperformed the girls significantly.

\section{Conclusion}

The aim of the study is to analyse how gender as a variable continues have an impact on the performance of Grade 10 to 12 mathematics learners, even at the Dinaledi Schools. The results show that only in two constructs, manipulative procedural knowledge and function concept in Grade 12 the boys outperformed the girls significantly. This could also explain the results of the others test scores, which are biased towards manipulative procedural knowledge and function concept. 


\section{References}

Agah, J., Lamido, S. \& Utibe, U. 2013. Gender differences in factors affecting academic performance of high school students, Journal of Research in Education and Society 4: 75-82.

Benbow, C.J. \& Stanley, J. 1983. Sex differences in mathematical reasoning ability, Science Journal 222: 1029-1031.

Carr, M., Steiner, H., Kyser, B. \& Biddlecomb, B. 2008. A comparison of predictors of early emerging gender differences in mathematics competency, Learning and Individual Differences 18: 61-75.

ChanLin, L. 2001. The effects of gender and presentation format in computer-based learning. Educational Media International 38: $61-65$.

Fryer, R.G. \& Levitt, S. 2009. An empirical analysis of the gender gap in mathematics, NBER Working Paper No. 15430.

Ganley, C.M. \& Vasilyeva, M. 2011. Sex differences in the relation between math performance, spatial skills, and attitudes, Journal of Applied Developmental Psychology 32: 235-242.

Khajehpour, M. \& Ghazvini, S. 2011. Gender differences in factors affecting academic performance of high school students, Procedia Social and Behavioural Sciences 15: $1040-1045$.

Kim, J. \& Chung, H. 2012. The role of family orientation in predicting Korean boys' and girls' achievement motivation to learn mathematics, Learning and Individual Differences 22: $133-138$.

Klein, A. \& Starkey, P. 1988. Universals in the development of early arithmetic cognition, Children's Mathematics San Francisco: JosseyBass 222: 27-54.

Livneh, I. \& Ayalon, H. 2013. Educational standardization and gender differences in mathematics achievement: A comparative study, Social Science Research 42: 432-445.

Matteucci, M. \& Mignani, S. 2011. Gender differences in performance in mathematics at the end of lower secondary school in Italy, Learning and Individual Differences 21: 543-548.

Mullis, I.V.S., Martin, M.O., Gonzalez, E.J. \& Chrostowsk, K.M. 2000. Tims's 2003 international mathematics report: Findings from IEA's trends in international mathematics and science study at the fourth and eighth grades. Children's Mathematics San Francisco: Jossey-Bass 222: 27-54.

Niederle, M. \& Vesterlund, L. 2010. Explaining the gender gap in math test scores: The role of competition, Journal of Economic Perspectives 24: 129-144.

Penner, A.M. \& Paret, M. 2008. Gender differences in mathematics achievement: Exploring the early grades and the extremes, Social Science Research 37: 239-253.

PISA. 2012. Are boys and girls equally prepared for life? OECD.

Robinson, P.J. \& Lubienski, S. 2011. The development of gender achievement gaps in mathematics and reading during elementary and middle school: Examining direct cognitive assessments and teacher ratings, American Educational Research Journal 48: 268302. 